\section{NOVA TELLVS}

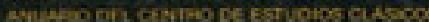

Nova Tellus

ISSN: 0185-3058

novatelu@servidor.unam.mx

Centro de Estudios Clásicos

México

FIERRO, María Angélica

Platón y los privilegios de los amantes

Nova Tellus, vol. 24, núm. 2, 2006, pp. 167-195

Centro de Estudios Clásicos

Distrito Federal, México

Disponible en: http://www.redalyc.org/articulo.oa?id=59120913007

- Cómo citar el artículo

- Número completo

- Más información del artículo

- Página de la revista en redalyc.org

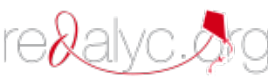

Sistema de Información Científica

Red de Revistas Científicas de América Latina, el Caribe, España y Portugal

Proyecto académico sin fines de lucro, desarrollado bajo la iniciativa de acceso abierto 


\title{
Platón y los privilegios de los amantes
}

\author{
María Angélica FIERRO \\ Universidad Nacional Autónoma de México \\ msmariangelica@yahoo.co.uk
}

\begin{abstract}
Resumen: Según las lecturas tradicionales del Banquete y el Fedro el amor y la creación poética en su sentido habitual serían despreciados por Platón frente a la actividad filosófica. Por otra parte, lecturas innovadoras proponen, en cambio, que en estas obras se presenta más bien en trágico conflicto dos concepciones del है $\rho \omega$ : por un lado, el amor a la Idea, que es des-instanciado e impersonal, y, por el otro, el amor como la pasión amorosa por un individuo en particular. Esta última interpretación conllevaría la valoración de la poesía como apropiada comunicadora de dicha experiencia. Defendemos aquí una exégesis alternativa a las dos mencionadas respecto al papel del enamoramiento, y también de la poesía, por parte de Platón en el Banquete y en el Fedro. Según la misma, el enamo-

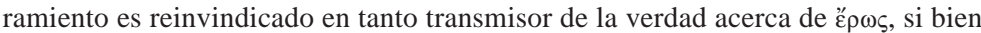
sólo a través de la filosofía los amantes, así como los poetas, pueden comprender el sentido trascendente de esta experiencia.
\end{abstract}

ABSTRACT: According to the most traditional interpretations in the Symposium and the Phaedrus, Plato scorns love and poetry in their usual form. On the other hand, according to some new ways of reading these same dialogues, he would be presenting two different conceptions of love in a tragic conflict: the philosopher's impersonal love for the Idea against love as the passion for an individual. Here a different understanding of this issue is suggested according to which Plato would be valuing the experience of falling in love, insofar as it is appropriate to

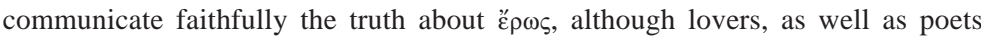
who narrate their love experience, are only able to comprehend the transcendental meaning of it by doing philosophy.

Palabras Clave: amor, Banquete, épws, Fedro, filosofía, Platón, poética, Sócrates, verdad.

RECEPCIÓN: 5 de septiembre de 2006.

ACEPTACIÓN: 18 de octubre de 2006. 



\title{
Platón y los privilegios de los amantes ${ }^{1}$
}

\author{
María Angélica FIERRO
}

\begin{abstract}
... que demostrando esto, que el amor no es enviado por los dioses en provecho del amante y el amado, [ese discurso] se lleve el premio. Por nuestra parte, es necesario para nosotros demostrar lo contrario: que es para la máxima buena fortuna que tal locura es concedida por los dioses.
\end{abstract}

Phdr., 245b4-c1

Las luces y las sombras del amor eran tan conocidas para los griegos como lo son hoy para nosotros mismos, así como la necesidad de simbolizar de algún modo la paradójica naturaleza de ع $\rho \omega \varsigma .{ }^{2}$ Los testimonios literarios nos cuentan de su intensidad, ${ }^{3}$ su fijación obsesiva y enferma en el objeto amoroso, ${ }^{4}$ su potencialidad constructora y creativa, ${ }^{5}$ así como de

\footnotetext{
${ }^{1}$ Las traducciones de los textos griegos mencionados, salvo que se indique lo contrario, son mías, en conformidad con las ediciones de los textos griegos del $T L G$. Las referencias a los textos griegos siguen también las ediciones del $T L G$, que en el caso de Platón es la de Burnet, 1901.

${ }^{2}$ Al mismo tiempo el dios del amor y la emoción de la pasión amorosa. Por

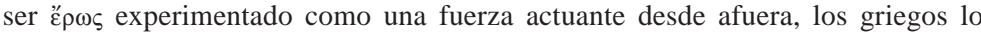
consideraban no sólo como un sentimiento sino asimismo como una divinidad, retratada artísticamente como un joven alado, quien eventualmente arroja flechas amorosas a sus víctimas. Cf. Dover, 1980, p. 1, Kitto, 1951, pp. 194-197, y Diez de Velasco, 2006.

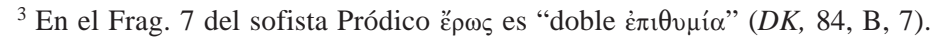

${ }^{4}$ En el Hipólito de Eurípides (vv. 27-28, 38-40, 1304) se reitera la idea de la pasión amorosa como una "mordida", una fuerza invasiva que se apodera del que se enamora, e incluso un "mal" o una "enfermedad" (vóøos).

${ }^{5}$ En la Lisístrata de Aristófanes, ép $\omega \varsigma$ es presentado como una fuerza que puede actuar incluso a nivel político y conducir hacia a la paz. Cf. Ar., Lys., vv. 550-554.
} 
su capacidad tanto de perdernos en la desgracia extrema, como de hacernos acceder a la más excelsa felicidad. También de su carácter obnubilante del sano juicio de hombres y dioses, ${ }^{6}$ y al mismo tiempo iluminante de un sentido y comprensión que de otro modo se nos oculta. ${ }^{7}$ Platón, seguramente en absoluto

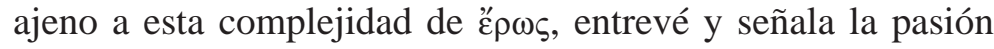
amorosa como una via regia de relacionarnos con la verdad. El Fedro otorga un lugar privilegiado a los amantes, quienes participan, junto con los poetas, los adivinos y los exorcistas, en una $\mu \alpha v i \alpha$ de origen divino. ${ }^{8}$ En el Banquete se despliega esta mirada innovadora sobre el erotismo humano de acuerdo con la cual el enamoramiento, que es a lo que habitualmente se refiere el griego antiguo con ع̋ $\omega \varsigma$, conserva un lugar especial en tanto experiencia primera que, si bien entendida, nos puede revelar y elevar al verdadero conocimiento. ${ }^{9}$

El presente trabajo trata de mostrar que el enamoramiento es para Platón un estado privilegiado, pues el amante, en la repetición de su discurso amoroso, enuncia algo verdadero, si bien sólo a través del quehacer filosófico es posible para él comprender el sentido de esta verdad que dice. De este modo ofrecemos una interpretación alternativa tanto a la tradicional, según la cual, en su teoría del amor, Platón en el fondo descalifica la pasión amorosa, y también la creación poética, en su sentido habitual y sólo valora la $\varphi \imath \lambda$ oбopía en tanto "amor a la sabiduría", ${ }^{10}$ como a lecturas más recientes, que sugieren que en el Banquete y en el Fedro se quiere en realidad presentar dramáticamente concepciones antitéticas e incompatibles del amor. ${ }^{11}$

Para cumplir nuestro objetivo nos centraremos en el texto del Banquete, donde veremos que en su diseño discursivo, no sólo se

\footnotetext{
${ }^{6}$ S., Ant., 793-794; Hes., Th., 120-122; Sapph., Fr. 31.

${ }^{7}$ Cf., p. e., Sapph., Fr. 34.

${ }^{8}$ Cf. Phdr., $244 \mathrm{a} 3$ y ss.

${ }^{9}$ Cf. Fierro, 2006.

${ }^{10}$ P. e. Bury, 1932, y Rowe, 1998, passim.

${ }^{11}$ Nussbaum, 1995, pp. 229-268.
} 
reproduce, como se ha señalado, la estructura del ع̋ $\rho \omega \varsigma$ en su carácter carente y $\mu \varepsilon \tau \alpha \xi \dot{v}$ o "intermediario". ${ }^{12}$ Además, la cadena

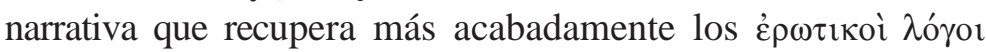
pronunciados en aquella inolvidable fiesta de Agatón, incluido el discurso de Diotima sobre la verdadera naturaleza y efectos del amor, está sostenida por Aristodemo, un "amante" o

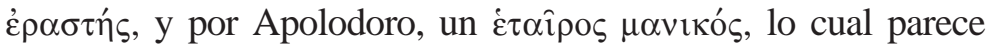
querer destacar dramáticamente que, en su condición de tales, poseen una capacidad especial para preservar y propagar con veracidad los mismos. En segundo lugar, proponemos una lectura del discurso de Alcibíades, según la cual este personaje es presentado, en tanto amante, como fiel informante de su experiencia amorosa, si bien incapaz de comprender el sentido de la misma, de modo que pudiera transformarla en indagación filosófica, conducente a la búsqueda de lo Bello, y con ello de lo Bueno. En el Banquete también se sugiere que el poeta es fehaciente transmisor de la verdad de los amantes, en tanto que el mito de Aristófanes de las mitades que añoran reencontrarse es una representación genialmente evocadora de la experiencia del enamoramiento, si bien el discurso de Sócrates-Diotima sugiere las limitaciones del poeta para interpretar el significado de la misma. Estas ideas del Banquete reaparecen, aunque en otro contexto, en el Fedro, donde se destaca el carácter excepcional de la experiencia amorosa y de la creación poética, en tanto, interpretadas a la luz de la actividad filosófica, pueden reconducirnos al conocimiento de la Idea de la Belleza.

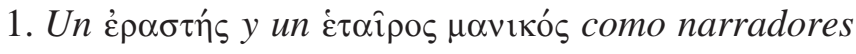

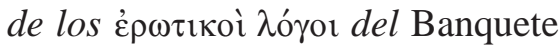

En algunos diálogos de Platón, en lugar de que el lector ingrese directamente en la acción dramática central, es introducido a

${ }^{12}$ Halperin, 1992. 
ella a través de algún o algunos personajes intermediarios del relato principal. Podríamos llamar a estos diálogos "narrados", y denominar al otro grupo "dramáticos". A su vez estos diálogos narrados pueden subdividirse en dos: aquellos en que el narrador es un testigo ocular de las cuestiones que nos informa, como por ejemplo Fedón en el diálogo homónimo, ${ }^{13}$ y aquellos en que el narrador depende del relato de un testigo presencial. En este último caso, el carácter indirecto de la transmisión aparece a veces acentuado porque no se trata de la primera narración que el actual narrador hace del hecho, sino que es la repetición de un relato anterior. ${ }^{14}$

Esta estructura mediatizada de los diálogos narrados aparece enfatizada en el Banquete, cuya intrincada organización ha sido apropiadamente descrita como un juego de muñecas rusas: ${ }^{15}$ Apolodoro va a repetir a un grupo de amigos no muy bien definido (173c2-3) lo que ha relatado a Glaucón hace dos días (172a1 y ss.). A su vez Apolodoro ha recibido el relato de Aristodemo (173b1-4), quien fue hace muchos años testigo ocular de la reunión. Por otra parte, cuando Aristodemo nos transmite las palabras de Sócrates, descubrimos que se trata no de un discurso propio, sino de las enseñanzas de una sacerdotisa, Diotima (201d1-212a7). Se mencionan además cadenas narrativas subsidiarias: Glaucón también recibió el relato, aunque de modo impreciso, a través de Fénix (172b3-4), quien,

\footnotetext{
${ }^{13}$ Dentro de esta clase puede reconocerse, a su vez, un subgrupo que se caracteriza por tener a Sócrates como narrador. Son los casos del Lisis, el Cármides, el Protágoras y la República.

${ }^{14}$ Por ejemplo, en el Teeteto, Terpsión y Euclides van a leer de un libro algo que ya ha sido redactado por Euclides sobre la conversación de Sócrates, Teodoro y Teeteto. Más intrincada es la red narrativa del Parménides: el narrador inicial es Céfalo, pero éste se encuentra con Adimanto y Glaucón, quienes se dirigen a casa de Antifón para escuchar de su boca el relato que recuerda de memoria desde adolescente de lo que le contó Pitodoro sobre la conversación que mantuvieron Sócrates, Zenón y Parménides, acompañados por Aristóteles y el propio Pitodoro.

${ }^{15}$ Nussbaum, 1995, pp. 229-268, en especial p. 232, y Halperin, 1992.
} 
de cualquier forma, resulta depender del relato de Aristodemo (173b1). Por otra parte, Apolodoro ha confirmado su relato con Sócrates (173b4-8). La intermediación narrativa está además intensificada por el uso, de principio a fin, del estilo indirecto. ${ }^{16}$ A ello hay que añadir que, a través de la diferencia de años que media entre la fecha dramática del relato inicial y la de la fiesta en casa de Agatón, se sugiere que la transmisión del relato ha sobrevivido de boca en boca por un tiempo considerable. ${ }^{17}$

Se ha señalado, respecto de este curioso diseño narrativo, la intención de querer reflejar en la forma misma del texto del

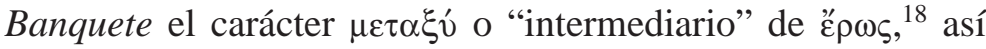
como de hacer vivenciar al lector la falta constitutiva del deseo como motor para la búsqueda de la verdad. ${ }^{19}$ A estas legítimas interpretaciones podríamos añadir algo más: a través de esta disposición textual se muestra también dramáticamente que los amantes tienen un lugar privilegiado como transmi-

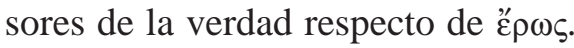

En el Banquete, el narrador principal es presentado como

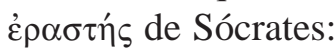

Era un tal Aristodemo de Cidateneo, un hombre pequeño, siempre descalzo, quien había asistido a la fiesta, por encontrarse

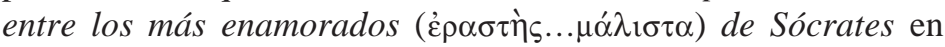
ese momento, según creo (cf. 173b1-4). ${ }^{20}$

\footnotetext{
${ }^{16}$ Hornsby, 1956-7; Fierro, 2001.

${ }^{17}$ El relato ha sobrevivido por un lapso de aproximadamente doce años, puesto que la fecha dramática de la fiesta en la casa de Agatón sería el 416 a. C. (Ath., Deip., 216f-217a), y la de la conversación inicial, alrededor del 404 a. C., teniendo en cuenta que en Ar., Ra., 83-85, del 405 a. C., se menciona el alejamiento de Agatón de Atenas referido también en Smp., 172c4. A este respecto, cf. Bury, 1932, pp. lxvi-lxvii.

${ }^{18}$ Cf. n. 16, supra.

${ }^{19}$ Halperin, 1992.

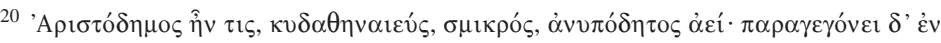

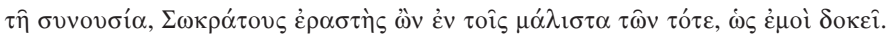




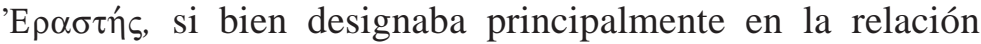
homoerótica característica de los tiempos de Platón al "amante", hombre mayor que cortejaba a algún bello y agraciado

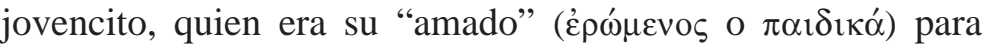
conseguir sus favores sexuales a cambio de instruirlo en la

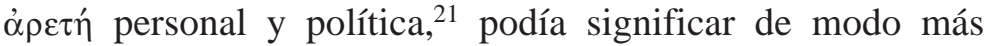
amplio "entusiasta", ${ }^{22}$ lo cual parece describir más apropiadamente el caso de Aristodemo.

Efectivamente, en el texto no se insinúa que Aristodemo estuviera consumido por una pasión que buscara la satisfacción de su deseo sexual en su frecuentación con Sócrates, como sí sucede en el caso de Alcibíades, ${ }^{23}$ sino que más bien se sugiere que sentía una admiración, ${ }^{24}$ rayana en el fanatismo, con respecto a su maestro. Se menciona, por ejemplo, su deseo de

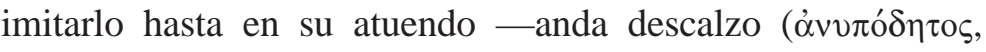
173b2) como él (220b6)—, y de frecuentar su compañía cuanto sea posible: acompaña a Sócrates a la casa de Agatón (174a3d3) y se queda con él en la fiesta, donde es recibido por ser un reconocido acólito de Sócrates, aunque probablemente no se aguardara especialmente su asistencia (174e5-8); 25 abandona el festejo junto con él y lo sigue al Liceo y a actividades cotidianas, lo cual se dice que era el proceder habitual de Aristodemo:

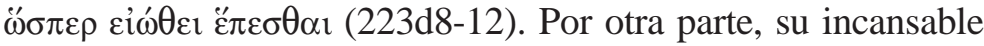
reiteración, por mucho tiempo ${ }^{26}$ y a diversas personas, del relato

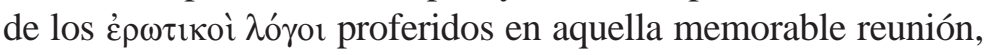
es una expresión de este fervor por todo lo que concierne a Sócrates.

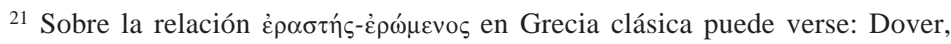
1978; Foucault, 1982, y Davidson, 1997.

${ }^{22}$ Cf. LSJ, s. v. غ̇ $\alpha \sigma \tau \eta \dot{\zeta, ~ y ~ D o v e r, ~ 1978, ~ p p . ~ 156-157 . ~}$

${ }^{23}$ En $217 \mathrm{e}-219$ e Alcibíades relata sus intentos de seducir a Sócrates.

${ }^{24}$ Rowe, 1998, p. 129.

${ }^{25}$ Dover, 1980, p. 83, y Rowe, 1998, p. 132.

${ }^{26}$ Cf. n. 17, supra.
} 
Es el relato de este "amante" de Sócrates, aunque sea en el sentido más amplio al que nos referimos, el que es presentado desde la construcción ficcional como el más ceñido a la verdad, frente a otras narraciones que son calificadas como "inexactas" y, de todos modos, dependientes de esta narración primera. ${ }^{27}$ Vemos entonces que dramáticamente, en tanto $\dot{\varepsilon} \rho \alpha \sigma-$ $\tau$ ins, Aristodemo es presentado como palmario transmisor y repetidor de discursos sobre el amor.

En cuanto al segundo narrador, Apolodoro, la razón por la que Glaucón en él encuentra el más apropiado relator de los discursos de Sócrates, en ocasión de la fiesta de Agatón, es, como leemos en $172 \mathrm{~b}$, que se trata de un asiduo compañero

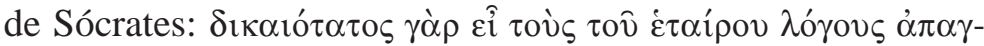
$\gamma \dot{\varepsilon} \lambda \lambda \lambda_{\varepsilon v v}$. Es cierto que $\dot{\varepsilon} \tau \alpha \hat{\imath} \rho \varsigma^{28}$ refiere, en principio, a una relación afectuosa más simétrica de camaradería y amistad, y no tanto a la devoción de una de las partes hacia la otra, como

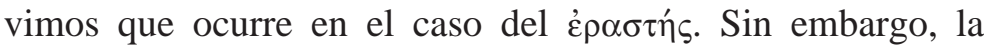
caracterización de Apolodoro es muy cercana a la de Aristodemo. En los tres años que ha estado con Sócrates no ha hecho más que ocuparse todos los días de informarse acerca

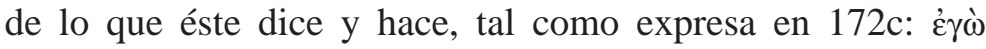

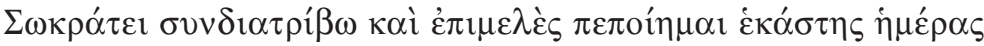

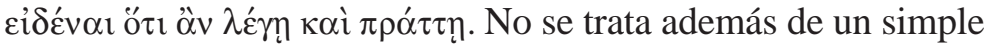
interés por Sócrates, sino de una admiración tan obsesiva que para él todos son seres desgraciados, excepto Sócrates, lo cual le ha ganado el sobrenombre de $\mu \alpha v$ iós. Así reflexiona el amigo con quien habla en 173d4-10:

Siempre el mismo, Apolodoro. Pues siempre insultas a ti mismo $\mathrm{y}$ al resto. Y me parece que consideras simplemente a todos

\footnotetext{
${ }^{27}$ Con respecto al relato de Fénix, comenta Apolodoro a Glaucón: П $\alpha v \tau \alpha \dot{\tau} \pi \alpha \sigma v$

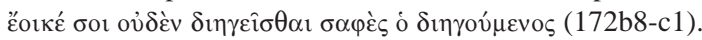

${ }^{28}$ Rowe, 1998, p. 129, señala justamente que Apolodoro es un غ̇ $\alpha \hat{\imath} \rho o \varsigma$, en

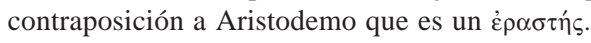


desgraciados, excepto a Sócrates, empezando por ti mismo. Y de dónde sacaste este sobrenombre de 'maniático' ( $\mu \alpha v i \kappa o ́ s)$ no tengo idea [pero es apropiado] puesto que ( $\gamma \alpha \dot{\alpha} \rho)$ en tus palabras siempre eres tal que te irritas contigo mismo y con el resto, excepto con Sócrates. ${ }^{29}$

Asimismo Apolodoro es presentado, como Aristodemo, ${ }^{30}$ ensayando y repitiendo este relato cada vez que tiene ocasión (172a1-2 y 173b10-c5).

Debe destacarse, además, que los discursos que Apolodoro y Aristodemo transmiten en el Banquete pertenecen a su vez a individuos que, más allá de representar distintos "saberes" del

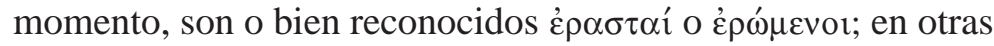
palabras, que han vivido en carne propia la experiencia amorosa —Erixímaco es presentado como el amante de Fedro; ${ }^{31}$ Pausanias, de Agatón; ${ }^{32}$ Alcibíades de Sócrates—, ${ }^{33}$ o bien se les adjudica, como su métier, un conocimiento especial sobre

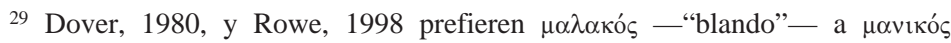
— "loco"-, ambos en los manuscritos, contra Burnet, 1901, y Bury, 1932. La razón es que, si la lectura es $\mu \alpha v ı$ cós, no se entiende la conexión causal sugerida por $\gamma$ ó $\rho$. Sin embargo, Denniston (1950, p. 62) muestra que es posible leer con

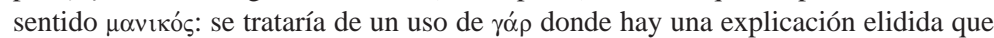
agrega el receptor con su pensamiento - "Y de dónde obtuviste... el ser llamado

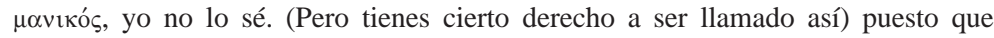

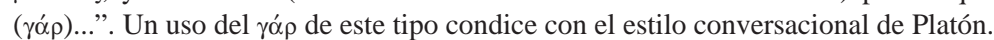
Lo que responde Apolodoro en 173e1-2" - “iy es tan evidente entonces que, al considerar así a mí y a ustedes, estoy loco ( $\mu \alpha i ́ v o \mu \alpha$ ) y desvarío?"- parece corroborar esta lectura. Sobre este punto ver especialmente Bury, 1932, p. 6.

${ }^{30}$ Sabemos que Aristodemo le ha contado esto al menos a Fénix y Apolodoro (173b1-2).

${ }^{31} 177 \mathrm{a} ; 223 \mathrm{~b} 7$.

32 176a4; 193b-c. En Prot., 315c-e, ya aparecen como parejas Erixímaco con Fedro, y Pausanias con Agatón. Dado que el encuentro de los sofistas del Protágoras habría acontecido c. el 430 a. C., desde un punto de vista dramático estas relaciones amorosas son representadas como habiendo perdurado a lo largo del tiempo (cf. n. 17, supra).

${ }^{33}$ Véase el discurso de Alcibíades y sus parlamentos desde que ingresa a la

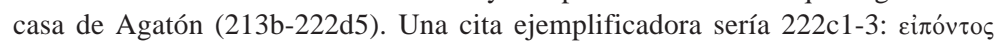

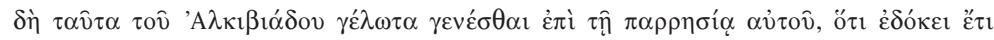

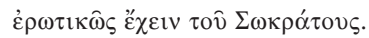


los asuntos amorosos, como es el caso de Aristófanes, en tanto poeta, y de Sócrates, en tanto filósofo. ${ }^{34}$

En el caso de Apolodoro se nos dice, además, que su fanatismo por Sócrates está ligado a una pasión por la filosofía. Así comenta Apolodoro en 173a1-3, acerca de su existencia en épocas previas a su frecuentación de Sócrates:

Antes de esto, andando de un lado para otro y creyendo hacer algo, era más infeliz que cualquiera, no menos que tú ahora mismo, pensando que se debía hacer todo tipo de cosas excepto filosofar.

En 173c2-5, expresa su incondicional interés de hablar, o de escuchar a cualquiera, acerca de la filosofía, como él mismo hará al contarles a sus amigos el relato de Aristodemo, tanto por el beneficio como el placer que obtiene de ello. Esta afición por la filosofía no sólo le hace despreciar todo tipo de asuntos, sino que le proporciona la certeza de un conocimiento: mientras los otros lo creen a él desgraciado, él en cambio "sabe" que ellos en realidad lo son.

Sin embargo, las intervenciones de Apolodoro, así como de Aristodemo, no reflejan en ningún momento que sean poseedores de un conocimiento de este tipo. La declaración de un saber tal suena en verdad más bien a una mera reproducción, sin que medie reflexión de lo que todo el tiempo escuchan de Sócrates estos acólitos.

Aristodemo no reaparece en ningún otro diálogo, pero la caracterización de Apolodoro en el Fedón confirma esta interpretación. Allí se halla entre los amigos íntimos de Sócrates que lo acompañan en sus últimos momentos, y es testigo, como Fedón, el narrador, de todo lo que allí se dice y hace. Pero, al final del diálogo, Apolodoro está lejos de mostrarse convencido por los argumentos de su maestro acerca de no temer a la muerte, al vislumbrarla como una liberación y al-

${ }^{34}$ 177d6-e3. 
cance de plenitud, sobre todo para aquel que ha llevado la vida filosófica, que, en el Banquete, Apolodoro dice admirar. Por el contrario, él es el único que llora desesperadamente en el momento que Sócrates debe beber la cicuta, al punto que éste amenaza con expulsarlo, como a las mujeres, si se muestra incapaz de refrenarse. ${ }^{35}$ Esta forma de actuar pone en evidencia su apego apasionado por el amigo querido que va a morir, así como su incapacidad de comprender los razonamientos filosóficos que Sócrates ha construido laboriosamente para convencer a sus amigos, entre otras cosas, de que nada de su persona que sea realmente valioso se va a desvanecer.

La virtud de personajes como Apolodoro o Aristodemo parece entonces consistir más bien en su facultad de repetir, con fidelidad e infatigable devoción, ${ }^{36}$ en tanto que admiradores apasionados de Sócrates y de sus dichos y acciones, aquellos discursos sobre है

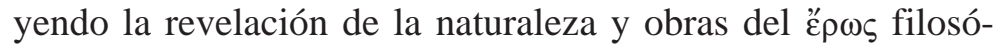
fico, cuando nos cuenten el discurso de Diotima- pero sin demostrar comprensión alguna del sentido de esta verdad que manifiestan. ${ }^{37}$

\section{Las experiencias de un enamorado: el discurso de Alcibíades ${ }^{38}$}

De acuerdo con la lectura más tradicional, el discurso de Alcibíades tiene la función de presentar a Sócrates como la encarnación del Eros filosófico descrito en el discurso de Sócrates-

\footnotetext{
${ }^{35}$ Fed., 117d3-6.

${ }^{36}$ En el Lisis, 204c-d, también encontramos representado dramáticamente este

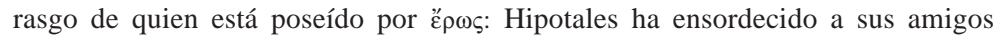
hablando sin cansancio de su amado Lisis.

${ }^{37}$ Halperin, 1992.

${ }^{38}$ Algunas de las ideas de este apartado y el siguiente son sugeridas en Fierro, 1999.
} 
Diotima. ${ }^{39} \mathrm{Y}$ sin duda hay elementos textuales que hacen incuestionable esta interpretación.

Las coincidencias entre Eros, que es esencialmente filósofo, y Sócrates pueden sintetizarse del siguiente modo: como el hijo de Poros y Penía, Sócrates está constituido en la falta: siempre anda descalzo $(203 \mathrm{~d} 1,220 \mathrm{~b} 6)^{40}$ y es pobre, puesto que desdeña los bienes materiales (203c6, 216e1); al modo del Eros acechador de lo bello (203d4), Sócrates siempre frecuenta a bellos jóvenes (216d2) y, como él, es maquinador de estratagemas y fértil en recursos (203d5-6) para estar junto a ellos (213c4-5, 223a6-7); se la pasa el día pensando (220c7), como un amante de la sabiduría (203d7); a la manera de un mago, sofista y adivino (203d6), él también profiere discursos encantadores (215e1-4), y es audaz de modo sobresaliente (203d5-6, 219d5). Es además un hombre maravilloso ( $\delta \alpha 1 \mu o ́-$ vı૬s) (219c1), así como Eros es un $\delta \alpha i ́ \mu \omega v$ intermediario entre los dioses y los hombres (202d13-e1). ${ }^{41}$

Finalmente Sócrates parece representar a aquél que, tal como dice Diotima en 212a4-5, habiendo alcanzado la virtud mediante la captación de lo Bello en sí, es generador de verdadera

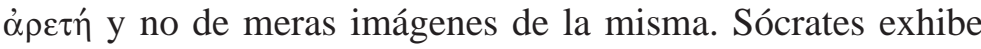
una moderación o autocontrol - $\sigma \omega \varphi \rho o \sigma v ́ v \eta$ - sobresalientes (216d7; 219d5): puede beber grandes cantidades de vino sin emborracharse (214a, 220a), no siente apego a los bienes materiales $(219 \mathrm{e} 1-3,216 \mathrm{e} 1)$, es capaz de resistir el frío del invierno sin cobijo (220a-c). Posee además una valentía —ỏv $\delta \rho \varepsilon i ́ \alpha-$ asombrosa (219d5), pudiendo soportar inclemencias intolerables para otros (220a1), ${ }^{42}$ al punto que ha sobrepasado en

\footnotetext{
${ }^{39}$ Bury, 1932, p. 1x; Dover, 1980, p. 164, y Rowe, 1998, p. 206.

${ }^{40}$ El calzado que lleva con ocasión de la fiesta de Agatón es una excepción: 174a3-4.

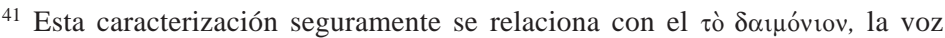
interior de Sócrates que lo disuade de hacer y que es al mismo tiempo una suerte de voz divina: Ap., 31d, y Phdr., 242c.

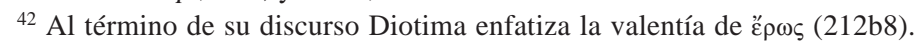


valor a los famosos generales griegos Alcibíades y Laques en las batallas de Potidea y Delio (220d3-221c1). Su devoción por el conocimiento es también extraordinaria: permanece sin descanso por días enteros en reflexión e investigación (220c37). No busca, por otra parte, como la mayoría, el reconocimiento de sus actos heroicos en los premios y honores de los hombres (220e6-7). Su recompensa debe estar entonces en algo superior, no accesible a la mayoría. Finalmente, como aquél correctamente iniciado en $\tau \grave{\alpha} \dot{\varepsilon} \rho \omega \tau \iota \kappa \alpha ́,{ }^{43}$ considera que hay una belleza más valiosa que la belleza física (218e4-219a2) y que

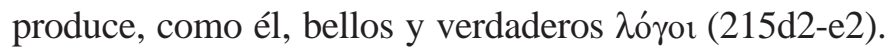

Considerando todos estos elementos, no hay dudas, entonces, de que al menos uno de los cometidos del discurso de Alcibíades sería plasmar a Sócrates como ejemplo vivo de quien ha

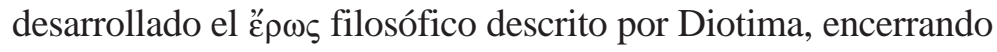
además probablemente una intención apologética con respecto al cargo de "corrupción a los jóvenes" sobre el que se continuaba debatiendo aún después de su ejecución y muerte. ${ }^{44}$

Sin embargo, como ha observado Sheffield, ${ }^{45}$ no es un mero elogio lo que presenta Alcibíades, sino más bien un texto complejo donde se mezcla la burla con la admiración, el amor con el rechazo, y que nos ofrece una paradójica representación de Sócrates, de modo tal que este finale del Banquete semeja el drama de sátiros ${ }^{46}$ de los festivales teatrales. ${ }^{47}$ Sócrates,

\footnotetext{
43 210b6-c3.

${ }^{44}$ Bury, 1932, p. lii, y Dover, 1980, p. 164.

${ }^{45}$ Sheffield, 2001.

${ }^{46}$ Véase la referencia en el texto mismo: Smp., 222d3-4.

${ }^{47}$ En el final de los concursos dramáticos de las Grandes Dionisias, luego de las tragedias y las comedias, se presentaba un drama de sátiros, que era el elemento más patentemente dionisíaco. No se conoce mucho acerca de las características del mismo, pero con los elementos conservados se puede conjeturar que en el drama satírico se retomaba la trama de la tragedia, mas se la representaba humorísticamente, lo cual implicaba modificaciones. Al yuxtaponer lo heroico

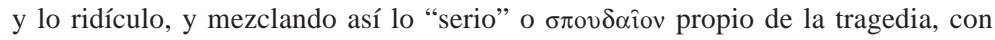

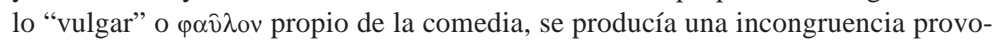




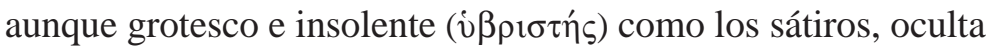
una naturaleza interna tan maravillosa que, al descubrirse, despierta estupor y devoción como si se estuviera ante "esta-

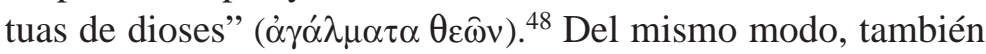
sus palabras poseen una doble condición: como la música de Marsias, encantan y subyugan, pero no son, como pueden parecer superficialmente, sólo razonamientos tramposos, para confundir al interlocutor. ${ }^{49}$ Sus $\lambda$ ó $\gamma$ or hacen estremecer a las personas y ver que llevan vidas indignas, como le ha ocurrido al mismo Alcibíades, quien, al escuchar a Sócrates, siente vergüenza y sabe que debería huir de los honores de los hombres y perseguir una vida filosófica. ${ }^{50}$

En su famoso libro The Fragility of Goodness, Nussbaum ${ }^{51}$ sugirió, por su parte, una interpretación polémica y novedosa del discurso de Alcibíades. Para ella Platón se propone darle voz allí a "otra" verdad acerca de la pasión amorosa. En contraposición al amor abstracto e impersonal del discurso de Diotima, encarnado en toda su crudeza por Sócrates, quien sólo ama a la Belleza en sí y desprecia a los individuos particulares, incluidas las personas, Alcibíades manifiesta sin ningún tapujo su enamoramiento por alguien en especial, Sócrates. Confiesa el $\pi \alpha ́ \theta$ os de la experiencia, cuenta la desgraciada historia de un amor no correspondido, y pone al descubierto la crueldad con que Sócrates lo ha tratado, al re-

cadora de humor. Este tratamiento de los temas de la tragedia, tales como la relación entre hombres y dioses, la ley y la justicia humanas, la guerra y sus consecuencias, ocasionaba una distancia y desplazamiento que permitían una mirada distinta sobre lo mismo. Sheffield, 2001, sostiene que el discurso de Alcibíades similarmente muestra al filósofo en sus notas más sublimes y ridículas a fin de sugerir al mismo tiempo la grandeza de sus designios y el carácter fallido de los mismos. Sobre el Banquete como festival dionisíaco cf. Sider, 1980.

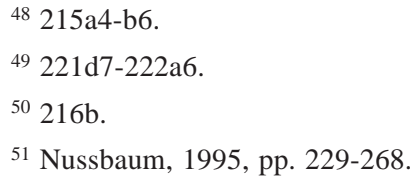


chazarlo. ${ }^{52}$ Para Nussbaum la intención de Platón en el Banquete sería entonces la de establecer una confrontación trágica entre dos concepciones de amor incompatibles: la del amor filosófico, desinteresado de las pasiones de este mundo, contrapuesta a la del enamoramiento por otro ser humano.

Por su parte, Rowe, ${ }^{53}$ expresando su desacuerdo con interpretaciones como la de Nussbaum, sostiene que el discurso de Alcibíades muestra que éste, lejos de haber accedido a "otra" verdad sobre el amor, no ha aprendido nada de sus experiencias con Sócrates, ya que: a) no comprende que Sócrates desea hablar con él y no tener una relación sexual; b) se ha negado a escuchar a Sócrates, a reconocerse como ignorante, a iniciarse en la filosofía y a cambiar su vida; c) en su encomio realiza una descripción de Sócrates que responde a la de Eros llevada a cabo por Diotima, pero sin saberlo y sin proponérselo, y sólo trata de acumular características sobresalientes (como los restantes expositores menos Sócrates), sin considerar si pertenecen o no a Sócrates.

Una interpretación que sintetiza y supera las existentes parece posible a la luz de nuestra tesis respecto al lugar privilegiado, aunque acotado, de los amantes en la transmisión de la verdad sobre el amor.

Alcibíades, enamorado y borracho, no realiza un acopio indiscriminado de rasgos notables de Sócrates, sino que dice la verdad - tal como él mismo insiste (cf. 214e6-215a1; $217 \mathrm{~b} 2 ; 217 \mathrm{e} 3-4 ; 219 \mathrm{c} 2$ ) — sobre su experiencia amorosa con Sócrates, tanto cuando describe las características y conductas de éste, como al referirse a sus deseos, sentimientos y pensamientos respecto de él. Alcibíades, no casualmente, representa a Sócrates con las verdaderas características de Eros, así como

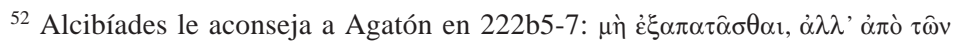

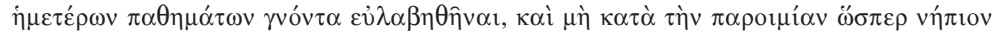

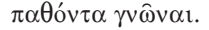

${ }^{53}$ Rowe, 1998, pp. 1-2.
} 
con las del verdadero amante, procreador de virtudes verdaderas, tal como señalara la crítica tradicional. Por otra parte, lejos de ofrecernos una alabanza ingenua de su amado, no duda en retratar con verdad la paradójica naturaleza de Sócrates, a la que refiriera el análisis de Sheffield, y en presentarlo, sin ambages, como realmente es, a la vez grandioso y ridículo. También cuenta sinceramente, como apunta Nussbaum, los desconsuelos del amor no correspondido por un individuo en particular, el desdén y falta de piedad que lo ha hecho sufrir la superioridad de Sócrates. A esto hay que añadir que Alcibíades no relata la historia de un amor común, sino un modo novedoso de amar y ser amado, generado por un amante de la sabiduría, un filósofo. Sócrates, a través de su propio obrar y vivir, ha hecho partícipe a Alcibíades de la

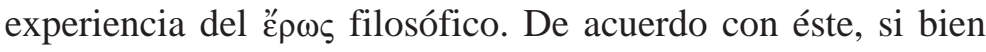
Alcibíades es despreciado en sus aspectos habitualmente considerados deseables — su belleza física, la concesión de sus

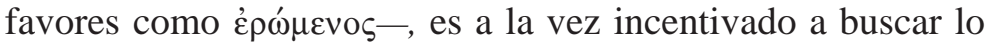
que es mejor para sí: abandonar los falsos éxitos mundanos y emprender él mismo el camino de la vida filosófica (215e8216c3). Con el artilugio de sus discursos, Sócrates ha movido a Alcibíades de su lugar acostumbrado y esperado de غ̇ $\rho \omega ́$ -

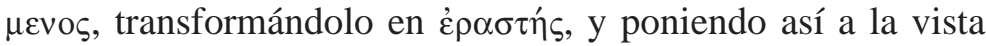
que Alcibíades no es bello y admirable, como todos lo creen, sino constituido esencialmente en la falta, sujeto de deseo. ${ }^{54}$ Sin embargo, aún desde esta nueva posición, Alcibíades, quien ha llegado tarde al discurso de Sócrates, ${ }^{55}$ se ha mostrado incapaz de comprender que la belleza, que ahora se descubre deseando, no se expresa completa en un individuo bello -ni

\footnotetext{
${ }^{54}$ Sócrates reconoce amar a Alcibíades (213c8-d1), pero lo hace de un modo particular, obligándolo a abandonar su lugar de amado (222a7-b4), de tal suerte

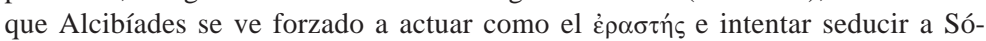
crates (cf. 217a y ss.)

${ }^{55}$ Cabe decir que Alcibíades aparece de pronto ( $\left.\dot{\varepsilon} \xi \alpha i ́ \varphi v \eta \varsigma\right)$ tras el discurso de Sócrates: Smp., 212c4-8.
} 
siquiera en el interior del fabuloso Sócrates-, porque él también es sujeto de deseo faltante, y no estatua divina y bella

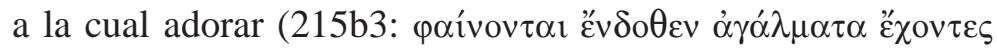

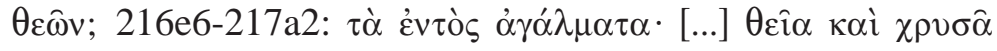

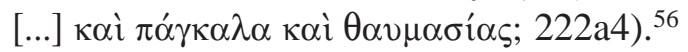

Sin embargo, aunque lo que dice Alcibíades, en tanto que enamorado, es verdad, sólo puede repetir pero no comprender su fidedigno relato. Dado su rechazo a iniciarse en la filosofía, Alcibíades no ha podido discernir el verdadero sentido de la nueva experiencia erótica a la que Sócrates ha tratado de conducirlo.

\section{El discurso de Aristófanes: el poeta como fiel transmisor de la experiencia de los amantes}

En el Banquete, los cinco discursos anteriores al de Sócrates son ejemplos de las disciplinas o prácticas que se disputaban el lugar del saber con la filosofía. En tanto tales, quedan ubicados en el texto, por un lado, como exposiciones acríticas acerca de ع̌ $\rho \omega \varsigma$, interesadas sólo en producir argumentos exitosos y no en la adecuación a la verdad, ${ }^{57}$ pero, por el otro, constituyen también en muchos sentidos una anticipación, aunque de modo fortuito, de algunas de las tesis centrales de la teoría del amor expuesta en el discurso de Diotima. ${ }^{58}$ A este respecto, la aportación de Aristófanes aparece en un lugar privilegiado en el Banquete, en relación con los otros cuatro

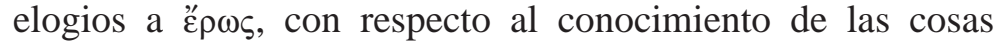
amorosas. En primer término, es el único personaje, junto con

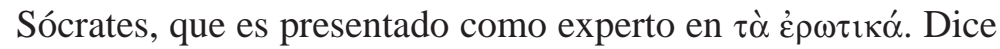

\footnotetext{
56 "A $\gamma \alpha \lambda \mu \alpha$ es una estatuilla sagrada de los dioses para adorar, honrar ( $\alpha \gamma \alpha \dot{\alpha} \lambda \lambda \omega)$. Cf. Juliá, 2004, p. 122.

${ }^{57}$ Cf. Nightingale, 1995, cap. 3, "Eulogy, irony and parody", esp. pp. 110-113.

${ }^{58}$ Sobre los discursos anteriores al de Sócrates ver Hunter, 2004, pp. 38-77.
} 
Sócrates cuando Erixímaco propone, por sugerencia de Fedro,

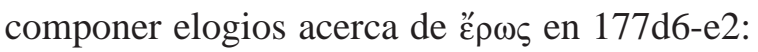

Nadie, Erixímaco, [...] te votará en contra. Pues en absoluto podría rehusarme yo, que digo no saber de otra cosa que de asuntos eróticos, ni por cierto Agatón y Pausanias; mucho menos Aristófanes, para quien su ocupación toda es sobre Dioniso y Afrodita.

Nos preguntamos cuál sería el sentido de este reconocimiento especial a Aristófanes, en contraste con los otros oradores, teniendo en cuenta: a) la agresiva crítica a la poesía presente en diálogos como el Ión, Apología, 22a8-c8, y República, 2-3, 376d9-402d9 y 10, 595a1-608b2, que consiste básicamente en que los poetas no tienen conocimiento de lo que hablan, y que producen, por otra parte, "copias" degradadas, que imitan las realidades sensibles, promoviendo el crecimiento de emociones y deseos perjudiciales y enseñando malos ejemplos de conducta; b) la invectiva contra Aristófanes, en particular en Apol., 18c8-d2, ${ }^{59}$ en tanto responsable de una adulterada representación de Sócrates como cosmólogo a la manera de Anaxágoras (Apol., 26d6-e4), la cual es considerada como una de las causas fundamentales de las falsas acusaciones que derivarán en su condena a muerte.

En forma similar a lo que vimos a propósito del discurso de Alcibíades, encontramos posiciones opuestas respecto a la valoración del parlamento de Aristófanes. Rowe juzga que este discurso no es más que una etiología de las relaciones sexuales, presentadas como un proceso biológico inconsciente, y que se trata, básicamente, de una historia divertida e inútil, cuyo único mérito sería, en todo caso, mostrar que el sexo como objetivo resulta insatisfactorio. Aristófanes no sería pre-

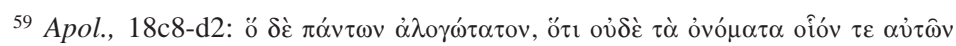

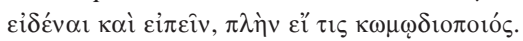


sentado, entonces, por Platón como un penetrante conocedor de la condición humana ni anticiparía en su relato la experiencia del "amor", sino un comediógrafo cuyo único talento era divertir. Esta caracterización coincidiría con la actitud de Platón en otros diálogos hacia los poetas: mostrar que, en comparación con el filósofo, son incompetentes para la educación de los jóvenes y, por eso, peligrosos. ${ }^{60}$ Esta interpretación se sitúa en las antípodas de la de Nussbaum, quien sostiene que, en este discurso, Platón se propone mostrarnos, en forma similar a la de Alcibíades, otra verdad acerca de ع́ $\omega \omega s$, la del enamoramiento por otra persona, en trágico contrapunto respecto al amor abstracto del filósofo.

Nuevamente parece que es posible entender la intervención de Aristófanes de un modo que explica tanto en qué sentido ambas interpretaciones son correctas, como la valoración especial, pero acotada, del poeta por parte de Platón.

Es cierto, como afirma Rowe, que la historia de las mitades que se buscan recurre, al modo de la comedia aristofánica, a los condimentos del humor y de la fantasía. Pero, no es tan infructífera y superflua como Rowe supone, puesto que allí no sólo se da cuenta de las relaciones sexuales humanas como un proceso biológico, sino también de algo más: el hecho de que nos sentimos como si alguna vez hubiéramos sido seres completos - no carentes - y de que a través de cualquier unión sexual buscamos entonces no sólo placer sino alcanzar, fallidamente, esta completud. Como dice Nussbaum, ${ }^{61}$ con el relato del encuentro de las mitades verdaderamente complementarias, Aristófanes, además del sexo (191b5-c8), da cuenta de otra experiencia humana: la del enamoramiento mutuo. En ella cada parte piensa que ha encontrado un otro tal que, al unirse a él en la relación sexual, se vuelve un ser completo (192b5-d2). Para conservar para siempre este ser que los hace

\footnotetext{
${ }^{60}$ Rowe, 1998 , p. 9.

${ }^{61}$ Nussbaum, 1995, pp. 229-268.
} 
sentir completos, los enamorados conciben como máximo anhelo su unión mutua incluso tras la muerte, simbolizado esto en términos extremos en su aceptación de la amalgama de Hefesto (192d2-e11). El poeta, Aristófanes, es capaz, entonces, de reflejar fidedignamente el papel central de las relaciones sexuales en la vida humana y las creencias de los amantes en el enamoramiento, tal como las entendería la sabiduría popular. ${ }^{62} \mathrm{Y}$ es en este sentido que posee, como los que se enamoran, un lugar privilegiado en la comunicación de la verdad de la experiencia del amor. Fracasa, sin embargo, como ellos, en la explicación: si practicara la investigación filosófica

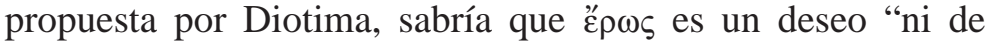
parte ni de todo" (205d10-e1), sino deseo de lo bueno, y que no hay un amado que nos completa, pues sólo es posible con él, esencialmente carente de lo bello y lo bueno como nosotros, procrear en la belleza. El poeta, entonces, como los enamorados, dice y es transmisor de la verdad acerca del amor, en tanto que refleja con autenticidad lo que es la experiencia erótica para los seres humanos. Lo que ocurre es que tampoco él comprende el sentido de esta experiencia que percibe, con acierto, como reveladora. ${ }^{63}$ Para comprender el significado de la misma es necesaria la filosofía. ${ }^{64}$

\footnotetext{
${ }^{62}$ Sobre cómo el discurso de Aristófanes, utilizando el género del "folk-tale", representa la sabiduría popular, al modo como sus comedias son reflejo también de la misma, véase Dover, 1966.

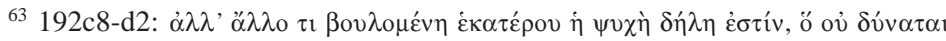

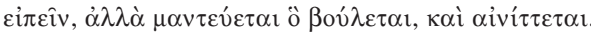

${ }^{64}$ Por otra parte, no se trata de que Platón rechace a la poesía per se. Por el contrario, tal como aparece sugerido en este discurso, el poeta puede en forma privilegiada comprender y transmitir la verdad. Pero se trata de transmitir una verdad

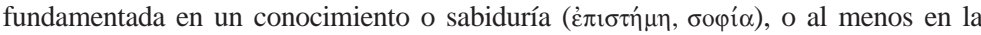
búsqueda de tal ciencia tanto como sea posible. Por lo cual, el verdadero poeta sería aquel que es al mismo tiempo filósofo. Con el Banquete mismo, que tiene muchos rasgos de comedia, Platón parece querer dar una muestra ejemplar de cómo se haría poesía filosófica. Cf. al respecto, p. e., Patterson, 1982, y Rowe, 1997.
} 


\section{La filosofía como hermenéutica de la experiencia amorosa}

El Fedro ratifica y expande lo sugerido en el Banquete respecto al lugar privilegiado de los amantes quienes, junto con poetas, adivinos y exorcistas, son partícipes de una $\mu \alpha v i ́ \alpha$ concedida por los dioses para su beneficio (Phdr., 244a3 y ss.). ${ }^{65}$

Allí se describe ampliamente y con evocadoras imágenes distintos aspectos del fenómeno del enamoramiento: la conmoción ante la visión de la belleza en el amado; la adoración del mismo como a un dios; las reacciones que acompañan al deseo erótico, tales como irrigación, sudor, acaloramiento, palpitación, irritación y picazón; alegría y alivio en la presencia del amado; sufrimiento en su ausencia; la obsesiva búsqueda de su compañía (Phdr., 251a1 y ss.). ${ }^{66}$

En forma similar a lo que veíamos anteriormente, la trastornadora experiencia de la pasión amorosa es valorada, en este caso, en tanto que, al poner al enamorado en contacto con lo bello, lo aparta de los intereses mundanos, constituyendo una vía excepcional de comunicación con lo divino. ${ }^{67}$ Pero, al mismo tiempo, el amante es, en general, incapaz de comprender el sentido de lo que le ocurre, ${ }^{68}$ y lo mismo podemos pensar que le acontece al poeta que también no es filósofo. ${ }^{69}$

Es a través de la actividad filosófica que se puede alcanzar el sentido de esta verdad que se manifiesta en el enamora-

\footnotetext{
${ }^{65}$ Sobre la $\mu \alpha v i ́ \alpha$ en la cultura griega antigua puede verse la tradicional obra de Dodds, 1963.

66 Platón posiblemente incluso tuvo su propia vivencia del enamoramiento, p. e., por Dión: $A P$, VII, 99.

${ }^{67}$ Phdr., 249d4-250b1.

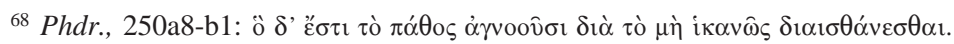

${ }^{69}$ En el Fedro, Platón pone en boca de Sócrates el mito del carro alado, que es una de sus más grandiosas creaciones literarias, no para reinvidicar la poesía per se, sino en cuanto que puede transformarse, como el amor, en poesía filosófica, es decir para "ascender" a las Ideas.
} 
miento. ${ }^{70}$ En forma análoga a lo que se plantea en la scala amoris del Banquete, ${ }^{71}$ el ejercicio de la dialéctica —que es, no casualmente, el tema de la segunda parte del Fedro- ${ }^{72}$ permite reconocer, a partir de la belleza del amado, la Idea de la Belleza, ${ }^{73}$ es decir, "recordar" las Ideas (las cosas preciosas - ahora perdidas - contempladas por el alma cuando se libera de la prisión del cuerpo), en particular la Belleza, sobresaliente entre todas por su claro resplandor. ${ }^{74}$ De este modo resulta que el enamoramiento podría revelarnos que nuestra existencia toda está signada irremediablemente por esa falla, ya que somos sujetos de deseo, constituidos en la carencia, no sólo, ni fundamentalmente, en relación con un individuo en

${ }^{70}$ Acerca de la propuesta de Nussbaum, 1995, pp. 269-310, en relación con el Fedro, nos parece que debe ser matizada. Platón valora sin duda el enamoramiento pero, al mismo tiempo, supone también en este diálogo que es necesaria la hermenéutica filosófica para comprender la trascendencia de esta experiencia. En oposición a Nussbaum puede verse Rowe, 1990.

${ }^{71}$ Cf. Smp., 210a1-212a8, donde se describen grados de conocimiento de la belleza, que consisten en el abandono de las instancias bellas y en una comprensión de creciente abstracción que podemos resumir del siguiente modo: En primer término, el amor a los cuerpos bellos ( $\tau \dot{\alpha} \kappa \alpha \lambda \alpha$ $\sigma \omega ́ \mu \alpha \tau \alpha, 211 \mathrm{c} 3-5$; véase también 210a5-b6) y la comprensión de una hermosura única e idéntica, común a todos

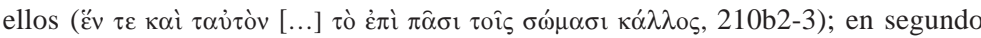
lugar, la apreciación de la belleza del alma como superior a la del cuerpo ( $\dot{\varepsilon} v$ $\alpha \hat{i} \varsigma$

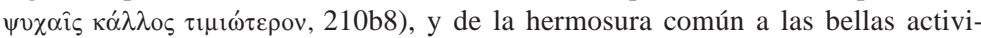

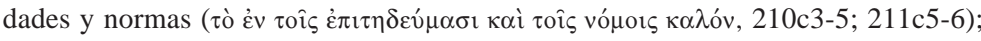

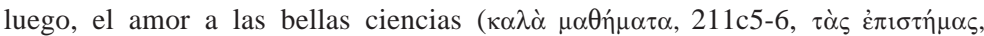

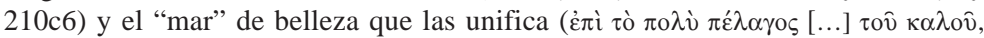
210d3-4); por último, la contemplación, para el que sea capaz, de la Belleza en sí

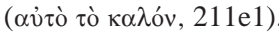

${ }^{72}$ El Fedro retoma el tema del है $\rho \omega \varsigma$ del Banquete pero desde otra perspectiva, siendo su tema la presentación del método dialéctico como fundamento filosófico de la verdadera retórica, el cual es ejemplificado en la primera parte del diálogo

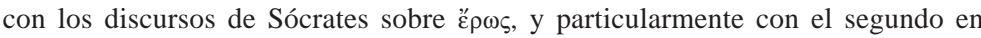
que el amor aparece insertado en una teoría del alma tripartita similar a la de República y al mismo tiempo proyectado a un nivel cósmico. Sobre la unidad del Fedro véase Rowe, 2000, pp. 7-11.

${ }^{73}$ Phdr., 249b6-d3.

${ }^{74}$ Phdr., 250b1-c6. 
particular - lo cual nos permitiría conservar la fantasía de que al poseer a ese individuo compensaríamos la falta de modo permanente-, sino en relación con la Belleza, imposible de hallar en su plenitud en instancia alguna, y sólo parcialmente accesible en forma des-instanciada en el caso de las almas humanas. ${ }^{75}$

Mucho se ha insistido en que, en la propuesta amatoria del filósofo, el individuo amado queda rebajado a mero objeto, al transformárselo en un medio de acceso a la Belleza, ${ }^{76}$ y que el amor filosófico es, por lo tanto, despersonalizado y rayano en la crueldad. ${ }^{77}$ Contrariamente, sin embargo, esta hermenéutica del enamoramiento que propone la filosofía no sólo nos permite descubrir el verdadero objeto de nuestro amor, sino también reinterpretar benéficamente nuestra relación con el amado. Éste deja de ser confundido con la Belleza en términos absolutos (que puede proporcionarnos, si alguna vez la alcanzáramos plenamente, una completud perdida y añorada) para ser reconocido también él como sujeto faltante y deseante.

Lo anterior se sugiere en el Banquete de diversos modos. Sócrates, quien se sabe a sí mismo, según se concluye del discurso de Diotima, como sujeto esencialmente deseante y carente, se empeña en lograr en sus "amados" este reconocimiento. En el diálogo con Agatón (199d1-201c9), no sólo trata de llevar a la comprensión de la naturaleza fallada del deseo precisamente a aquél que al elogiar a "Е $\omega$ s se ha ala-

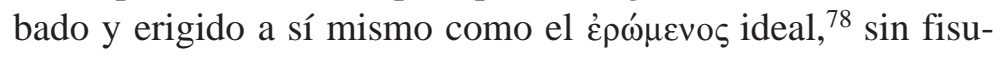

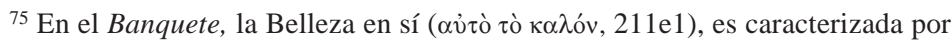
ser: pura, es decir, que posee como su única propiedad el ser bella sin estar mezclada con otras propiedades, tal como ocurre en las cosas concretas; absoluta, esto es, no relativa al momento, al lugar o a quien realiza el juicio de belleza; inmutable e idéntica a sí misma, divina, y de la cual las cosas bellas participan sin que la Belleza en sí crezca o disminuya (211a1-b5).

76 Vlastos, 1973.

${ }^{77}$ Nussbaum, 1995, pp. 229-268.

${ }^{78}$ Todos los elogios a "E $\omega \omega \varsigma$ en el Banquete tienen rasgos auto-referenciales, aunque no sea más que a la profesión o actividad propia de cada uno de los
} 
ras; además, a través de la refutación, trata de generar en él, aunque de manera infructuosa, ${ }^{79}$ el reconocimiento de su ignorancia (201b11-12), es decir, de la carencia de sabiduría, lo que le que le permitiría descubrirse como sujeto deseante de lo bello y de lo bueno. Por otra parte, ya hemos visto que Alcibíades da testimonio, aunque sin saberlo, del modo particular en que ha sido amado por Sócrates, justamente obli-

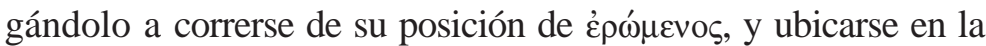

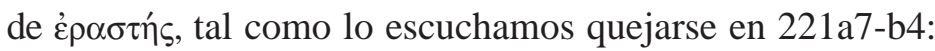

Y ciertamente, no sólo a mí, sino también a Cármides, Glaucón, y a Eutidemo de Diocles, a quienes éste [i.e. Sócrates], haciéndose

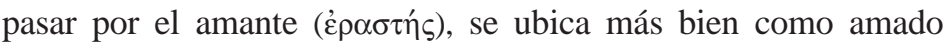

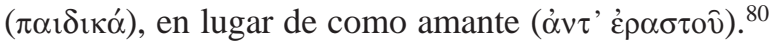

La historia de Aristófanes de los seres humanos divididos que intentan reunirse con su fracción originaria, ya sugería cómo en la experiencia del enamoramiento mutuo se vuelve inesquivable para ambas partes el percibirse como sujetos incompletos y deseantes. ${ }^{81}$ Por su parte, en Phdr., 255a1-256a6, se desarrolla una idea similar pero de mayor complejidad con la

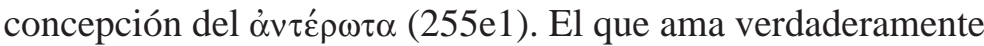
transforma a su vez en amante al amado, en tanto la belleza que en él descubre se refleja en su mirada y la corriente de deseo rebota sobre el amado, generando deseo en él, aunque esto le resulte al mismo incomprensible. ${ }^{82} \mathrm{Si}$ ocurriera

oradores, pero esto es particularmente cierto en el caso del discurso de Agatón quien, al retratar a "E $\rho \omega_{\varsigma}$, está realizando un obvio retrato de sí mismo como el

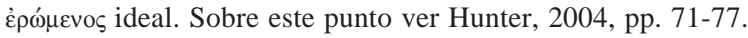

79 201c6-7.

80 Éste quizá da una clave para entender la famosa frase de Lacan: "amar es dar lo que no se tiene a aquél que no lo es": Sócrates, quien se apercibe a sí mismo como sujeto carente y deseante, trata de suscitar este mismo reconocimiento en aquellos que ama. Cf. Lacan, 1982, y Le Brun, 2004.

${ }^{81}$ Cf. Halperin, 1986 y 1990.

${ }^{82}$ Phdr., 255d3-4. 
que ambos fueran filósofos, ${ }^{83}$ podrían entender que el enamoramiento les señala en realidad una falta más esencial: la de la Belleza en su plenitud que alguna vez pudieron contemplar. Pero aún si éste no fuera el caso, la vivencia plena del mutuo amor conlleva al menos el premio de auténtica felicidad. ${ }^{84}$

Hemos visto, entonces, que la experiencia de la pasión amorosa para Platón es una vía especial de comunicación con lo divino en la que se manifiesta una verdad fundamental para nosotros, que somos sujetos carentes y deseantes de lo bello y lo bueno. Los enamorados son óptimos transmisores de dicha experiencia, pues quién mejor que aquel que la ha vivido para contarnos cómo realmente es. Los verdaderos poetas, por su parte, igualmente receptores inspirados del ámbito divino, también son capaces de reflejar con fidelidad las características de esta experiencia. Sin embargo, puede ser que ni unos ni otros nunca comprendan el sentido profundo de lo que allí ocurre. Sólo a través de la hermenéutica filosófica se puede descubrir que somos portadores de una falla más esencial y originaria: en tanto que lo que deseamos en realidad es la Belleza en su completud, nada de este mundo puede totalmente satisfacer nuestro anhelo. Nada más nos queda reconocernos como buscadores perpetuos de lo Bello y esperar que sólo alguna vez fugaz y parcialmente lo hayamos podido o podamos alcanzar. Para Platón, más que "condenados a ser libres", estamos forzados, sepámoslo o no, a દ́pồ.

\footnotetext{
${ }^{83}$ Phdr., 256b1 y ss.; 252e1-253b1; 254b3-7.

${ }^{84}$ Phdr., 256d6-e2.
} 


\section{BIBLIOGRAFÍA}

\section{Obras de referencia}

DK = Diels H. and Kranz W., Die Fragmente der Vorsokratiker, Berlin, Weidmannsche, 1951-2.

LSJ = Liddell H.G.-Scott D.D.-Jones H.S., Greek English Lexicon, Oxford, Oxford Clarendon Press, 1940.

$T L G=$ Thesaurus Linguae Graecae

Fuentes antiguas: ediciones, comentarios y traducciones de Platón

Burnet I., Platonis Opera, 5 vols., Oxford, Oxford University Press, 1901.

Bury, R. G., The Symposium of Plato, ed. con introd., nts. y com., Cambridge, Cambridge University Press, 1932.

Dover, K., Plato. Symposium, ed. con introd. y com., Cambridge, Cambridge University Press, 1980.

JuLié, V., Platón. Banquete, introd. con trad. y nts., Buenos Aires, Losada, 2004.

Platón, El banquete, trad. L. Gil, Madrid, Aguilar, 1969.

-, Diálogos III: Fedón, Banquete, Fedro, trad., introd. y nts. C. García Gual, M. Martínez Hernández, E. Iñigo Lledó, Madrid, Gredos, 1997.

Robin, L., Platon. Oeuvres Complètes IV. Le Banquet, ed. con introd. y nts., Paris, Les Belles Lettres, 1951.

Rowe, C. J., Plato. Symposium, ed. con trad. y com., Warminster, Aris \& Philips Ltd, 1998.

—, Plato. Phaedrus, introd., trad. y com., Warminster, Aris \& Philips Ltd, 1998.

Vicaire, P., Platon. Oeuvres Complètes. Le Banquet, introd. L. Robin, Paris, Les Belles Lettres, 1992.

\section{Obras contemporáneas}

DAVIDSON, J., Courtesans and Fishcakes: the consuming passions of Ancient Greece, New York, St. Martin's Press, 1997.

Denniston, J. D., The Greek Particles, Oxford, Oxford Clarendon Press, 1934.

Diez De Velasco, F., "La iconografía de lo erótico en el mundo griego antiguo: de lo divino a lo físico", Revista del Museo de Bellas Artes de la Coruña, 1, 2006 (en prensa). 
Dodds, E. R., The Greeks and the Irrational, Los Angeles, University of California Press, 1963.

Dover, K. J., “Aristophanes'speech in Plato's Symposium”, Journal of Hellenic Studies, 66, 1966, pp. 41-50.

—, Greek Homosexuality, Cambridge, Harvard University Press, 1978.

Fierro, M. A., Reseña de C. J. Rowe, Plato: Symposium, 1998, Méthexis XII, 1999, pp. 146-149.

—, "Narrar el verdadero amor", en V. Julia (ed.), Los antiguos griegos y su lengua, Buenos Aires, Biblos, 2001, pp. 23-38.

_, "El concepto de $\mu \varepsilon \tau \alpha \xi u ́$ en el Banquete de Platón", Actas del Congreso Nacional de Filosofía, Universidad Nacional Autónoma de México, 2006 (en prensa).

Foucault, M., Historia de la sexualidad 2: El uso de los placeres, trad. Ulises Guinazu, México, Siglo Veintiuno, 1982.

HALPERIN, D. M., "Plato and the erotic reciprocity", Classical Antiquity, 5, 1986, pp. 60-80.

-, "Why is Diotima a woman?", en D. M. Halperin (ed.), One Hundred Years of Homosexuality and Other Essays on Greek Love, Londres, Routledge, 1990, pp. 113-151, 190-211.

-, "Plato and the erotics of narrativity", en Oxford Studies in Ancient Philosophy, vol. supl., Oxford University Press, 1992, pp. 113-129.

Hornsby, R., "Significant action in the Symposium", Classical Journal, 52, 1956-7, pp. 37-40.

Hunter, R., Plato's Symposium, Oxford, Oxford University Press, 2004.

Kitto, H. D. F., The Greeks, Harmondsworth, Penguin, 1951.

Lacan, J., La transferencia, trad. T. Pizarro, C. Meyer y M. Mocchiutti, Buenos Aires, Escuela Freudiana de Buenos Aires, 1982.

Le Brun, J., El amor puro. De Platón a Lacan, trad. S. Mattoni, Buenos Aires, Literales, 2004.

Nightingale, A. W., Genres in dialogue: Plato and the construct of philosophy, Cambridge, Cambridge University Press, 1995.

Nussbaum, M., "El discurso de Alcibíades: una interpretación del Banquete", en La fragilidad del bien: fortuna y ética en la tragedia y filosofía griega, trad. A. Ballesteros, Madrid, Visor, 1995, pp. 229-268.

_, “ 'No es cierto ese decir': locura, razón y retractación en el Fedro, en La fragilidad del bien: fortuna y ética en la tragedia y filosofía griega, trad. A. Ballesteros, Madrid, Visor, 1995, pp. 269-310.

-, and J. Sinvola (eds.), The Sleep of Reason, Chicago, The University of Chicago Press, 2002.

SheFfield, F., “Alcibiades' speech: a satyric drama”, $G \& R, 48,2001$, pp. 193-209. 
Patterson, R., “The Ascent in Plato's Symposium", Proceedings of the Boston Area Colloquium in Ancient Philosophy, 7, 1991, pp. 193-214.

-, "The Platonic art of comedy and tragedy", Philosophy and Literature, 6, 1982, pp. 76-92.

Rowe, C. J., "Philosophy, Love and Madness", in C. Gill (ed.), The Person and the Human Mind: issues in ancient and modern philosophy, Oxford, Oxford University Press, 1990, pp. 227-246.

_, "Plato: aesthetics and psychology", in C. C. W. Taylor (ed.), From the Beginning to Plato, Londres, Routledge, 1997, pp. 425-455.

Sider, D., "Plato's Symposium as Dionisyan festival", QUCC, 33, 1980, pp. 41-56.

Vlastos, G., "The individual as an object of love in Plato", en G. Vlastos, Platonic Studies, Princeton, Princeton University Press, 1973, pp. 3-42. 
